\title{
Meeting diversity during the covid-19 pandemic in a fully online learning environment
}

\section{Anja Pfennig}

HTW Berlin, Universitiy of Applied Sciences HTW Berlin, Berlin, Germany.

\begin{abstract}
Diversity among engineering students is growing more and more acknowledgeable in higher education - especially in first year classes where in applied universities students from many backgrounds form new classes. Differences in education (high school, job training, dual careers, etc.) are as common as various social aspects (family duties, etc.) that delay full time studying. This challenges students as well as lecturers especially in the covid19 pandemic of 2020/2021. A standard based portfolio grading enables students to participate and place different skills in their cumulative assessment. The online course structure using Moodle as content management system is based on inverted classroom teaching scenarios. These are supported by peerto-peer lecture films and micro-lectures along with various online teaching materials and online meeting sessions. The portfolio cumulatively grades lectures, presentations, forum discussions, written homework and glossary entries. Although benefits of present classes are obvious the course results improved over previous semester especially for students with language difficulties. This paper reflects on the possibility to meet diversity in the covid19 pandemic and enable first year mechanical engineering students to grow more homogeneous regarding scholarly work.
\end{abstract}

Keywords: Diversity; language skills; lecture film; inverted classroom; first year students. 


\section{Introduction}

Especially in first year classes where in applied universities students from many backgrounds form new heterogeneous classes diversity among engineering students is growing more and more acknowledgeable in higher education. Student backgrounds differ in education as well as social aspects hindering full time studying, e.g. they may enroll directly from high school, have had job training, or went for dual careers. Some are taking care of little children or supporting elderly family members. With the covid-19 pandemic more personal problems enter the study schedule. Generally, high school students had good education in math, physics and chemistry whereas students with job histories have advantages in applied subjects such as technical mechanics, design or material science: Pfennig (2020). Because as a future maker of things students should investigate and learn with a strong practical motive: Ashby et al. (2013), Pfennig (2016), Pfennig (2018). Therefore, at HTW-Berlin, Germany, Material Science is taught based via "design-led" teaching approach: Ashby et al. (2013) including inverted classroom teaching scenarios: Berret (2012), Brame (2015), Pfennig (2016), Pfennig (2018), Pfennig (2019). Here, students study the science on their own without time limit and then take time to raise questions and discuss details, solve hands-on problems, perform group work and master difficult problems in class. Setren et al. (2019) reports success for the "inverted classroom" teaching method only for MINT courses neglecting progress for economic related teaching. Still, it enables students to discuss early and communicate in a scientific related course such as Mat. Sci. in equal measure: Pfennig (2016), Pfennig (2018).

In general, grading and reporting on student learning continue to challenge educators especially in divers classes. The educational benefits of standards-based: Sadler (2005) versus the traditional score-based grading have been modelled quantitavely by: Marbouti et al. (2016) showing that standards-based grading is based on "the measurement of the quality of students proficiency towards achieving well defined course objectives": Heywood (2014). But, only if the grading provides quality information about student learning, is carefully planned and excellently communicated it is successful: Guskey and Pollio (2012). Standardsbased assessments provide clear, meaningful, and personalized feedback for students related to learning objectives if the course objectives are well defined beforehand: Heywood (2014).

Especially time limited exams with strong focus on verbal expression not mathematically precise description penalize students with language or reading difficulties. Morover, presentations, answering questions and group discussions are also of disadvantage to students with language difficulties and to those insecure of presenting results - especially in a digital online environment. Students with outside of university duties, care of family relatives and personal problems will face difficulties turning in semester-homework on time. The cumulative assessment of the Material Science course introduced earlier: Pfennig (2018), Pfennig (2019), Pfennig (2020) offers a promising alternative to meet diversity - especially in a fully online teaching environment, such as summer and winter semester 2020/2021. 


\section{Course structure and assessment}

The originally blended learning course approach: Pfennig (2018), Pfennig (2020) was restructured to meet the requirements of full online teaching and assessment in summer and winter semester 2020. Usually, face-to-face time is 4 hours/week accounting for 6 ECTS. To shift the focus towards the learning progress and at the same time acknowledge different learning skills and abilities the course assessment was decentralized: Pfennig (2020). Widely differing cumulatively adding activities were established over the 12 to 16 weeks of the semester with regard to the learning objectives (Figure 1). Scientific peer-to-peer lecture films: Pfennig (2018), Pfennig (2019) and micromodule lectures provided via the content management system Moodle are the main learning resources. In addition different teaching materials e.g.: worksheets and worked solution, mindmaps, glossaries, memory sheets, online tests and web-based-trainings WBT are available: Pfennig (2016), Pfennig (2018). Weekly online teaching sessions using big blue button and zoom were invariably used for clarifying, answering questions, role plays and hands-on tasks in break-out rooms. According to the inverted classroom teaching approach knowledge transfer was rigidly set for the guided selfstudy periods only. This concept refers and applies to different learning styles, possible language problems and different personal, social, scientific and ethnic backgrounds of most of the averagely 45 students per semester, as first introduced in: Pfennig (2020).
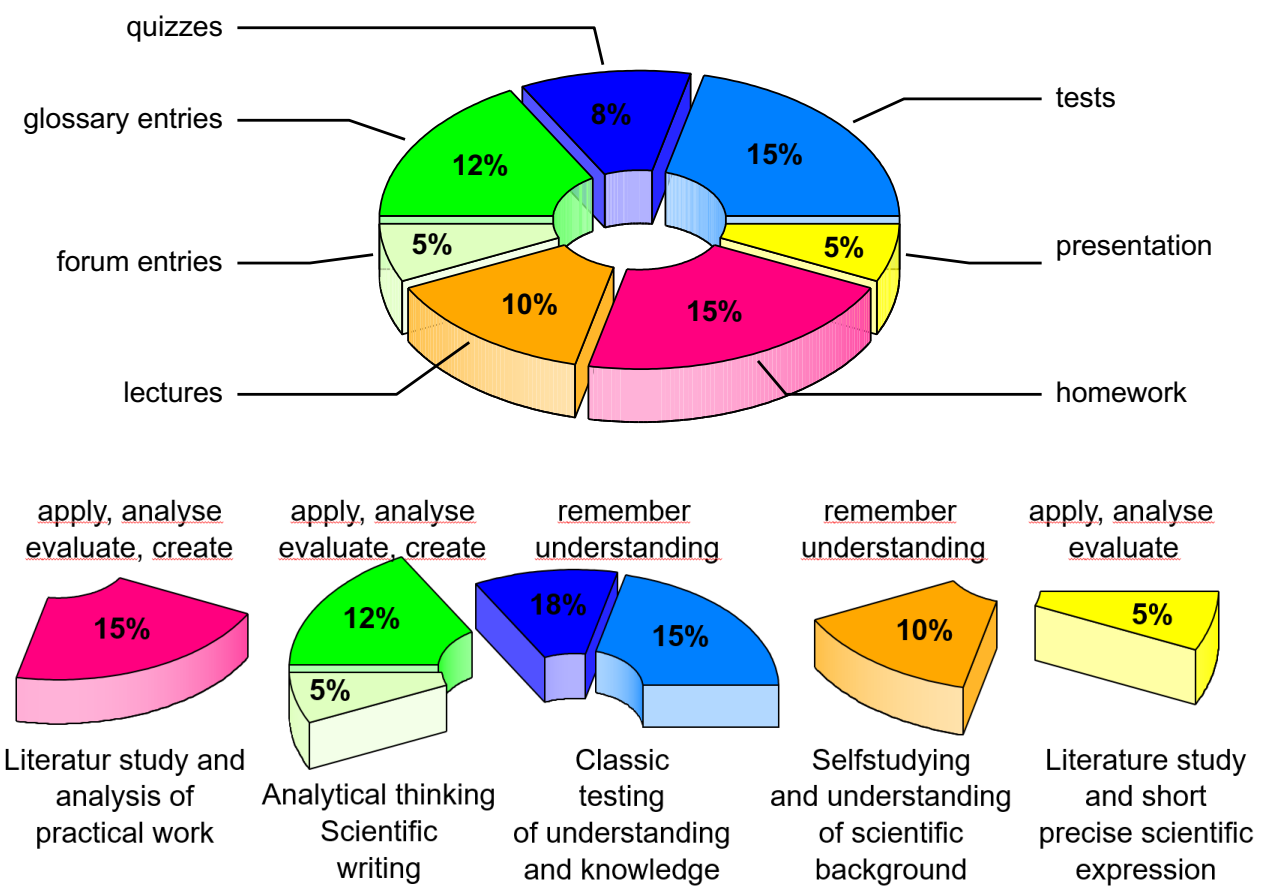

Figure 1. Grading Assignments (top) and main learning outcomes (bottom) in the Moodle based materials science course (5 ECTS). 
Moodle provides an excellent basis to establish graded activities that are followed or accompany each lecture or theme: Pfennig (2018). All semester activities (50 points) were weighted appropriately and implemented as compulsory. The final Moodle exam based on tests during the semester counts for 10 points (in sum 60) with progressing credits towards the end of the semester to to prevent students from stopping to study after they reached the necessary 30 points to pass the course. Alternatively, up until the final week of the semester students could choose to take a final exam instead of the cumulative course assessment counting for all students transferring in the middle of the semester, repeating students and those coming from different study subjects.

\section{Course results with regard to the online semester SS2020}

Due to data restriction on students social background the diversity of the course is exemplary stated by the language background (Figure 2). Averagely students scored $40(\mathrm{C}+)$ out of 60 possible points in 2015/16, 49 (B) in SS2016, 54 (A-) in WS2016/17, 36 (C) in SS2017, 42 (B-) in SS2018, 39 (C+) in SS2019 and 43 (B-) in SS2020. The summative assessment of the course does not indicate significant improvement of learning outcome when students were requested to study during the entire semester. However, it is noteworthy and important to consider the grade distribution: The cumulative Moodle course assessment offers more students access to good grades, such as A- to A+ compared to the course assessment via final exam. It is very important to know about the special situation in Germany: since 2015. Refugees mainly from the Arabic peninsula, Syria, Libanon, and partly from the Maghreb, Tunisia, Marokko and Egypt are involved in asylum affairs and students with very little language skills enroll into applied Universities to start or finish studies. In summer semester 2018 these students were allowed to enter without the otherwise necessary DSL-2 language certificate (B2, C1 average): Pfennig (2020) and also in SS2019 students were allowed to postpone their language certificate until the third semester. Despite good engineering capabilities the missing language skills severely constrain learning progress and success (Figure 2). However, even in summer semester 2018 fewer students failed the class when their background was non-native German speaking which was not repeated in SS2019. The best course grade for GSL (german as a second language) students in SS2018 was B+ and in SS2019 B. In SS2020, however, even GSL-students scored A+ and non of these students failed the class. In SS2020 the Corona-Pandemic requested all courses to be taught fully online. Face-to-face time was exchanged for online sessions with hardly interactions of the first year students at all. Still, especially students with migration background were very eager to study and follow the course on an weekly basis. The grade average in SS2020 does not differ significantly from previous semester. However, GLS-students significantly score better in an online setting than blended learning setting This clearly indicates that the cumulatively 
assessed Moodle course is successful even in a fully remote setting.

In the blended learning setting of SS2018 and SS2019 approximately 30\% of the students with German as second language GSL did not attend the face-to-face time with exception of the explicit inverted classroom scenarios with lecture captures as mandatory preparation and small group work during class. They explained that they did not understand the lecture due to their lack in language understanding and had to look up many words and sentences in a dictionary and that is was much easier and successful in terms of learning outcome to study at home with their peers. During the online semester of the covid-19 pandemic students at home now had enough time to read, look up words, discuss, exercise and understand using the different learning materials provided in the Moodle course: Pfennig (2018). Feedback given during online-sessions was rated valuable and reflected the students`study progress.
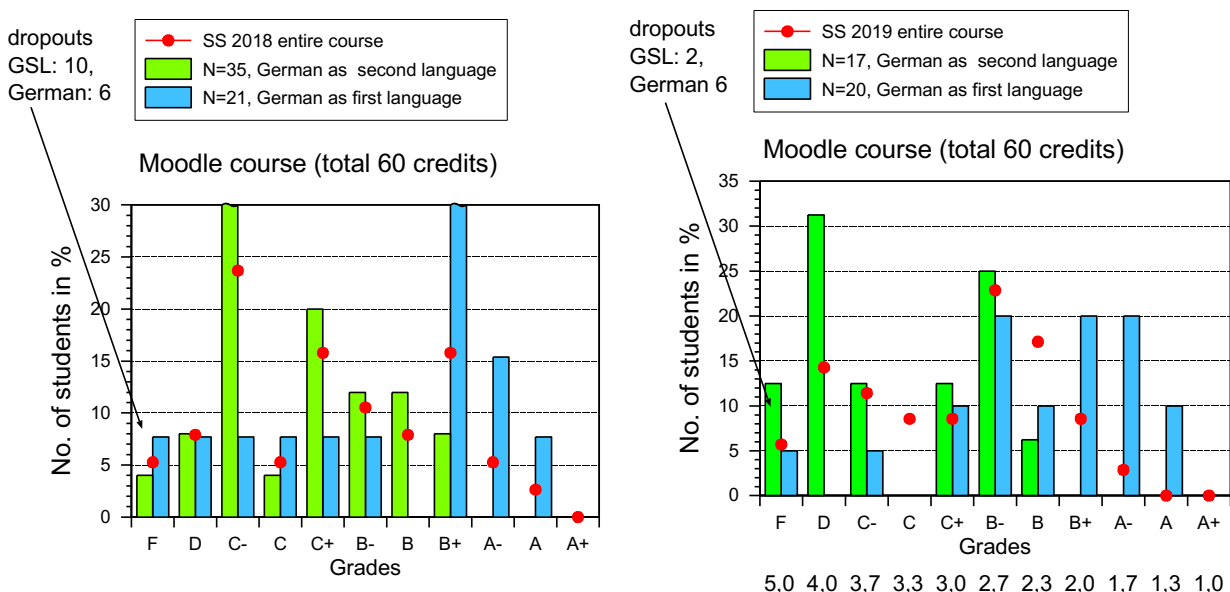

$\begin{array}{lllllllllll}5,0 & 4,0 & 3,7 & 3,3 & 3,0 & 2,7 & 2,3 & 2,0 & 1,7 & 1,3 & 1,0\end{array}$
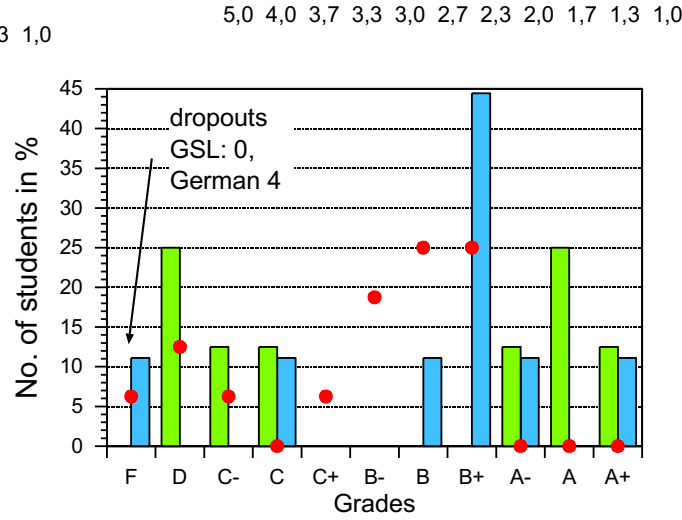

$\begin{array}{llllllllllll}5,0 & 4,0 & 3,7 & 3,3 & 3,0 & 2,7 & 2,3 & 2,0 & 1,7 & 1,3 & 1,0\end{array}$

Figure 2. Material science course results SS2018 to SS2019 (blended learning) and SS2020 (full online course) accounted for German as a first and second language applying the cumulative Moodle-based assessment). 


\section{Evaluation}

Despite all negative aspects of the covid-19 pandemic and required fully online-semester the possibility for students in a first year material science class to study in their own velocity and to work on projects in small groups with their peers seems to be beneficial for the diverse student group and especially for students with German as a foreign language. Also, the possibility of the lecturer explaining details according to the special needs allowed students to approach hands-on problems skillfully. Students who had to work or take care of family members could participate without knowledge loss, because the Moodle course offers time and place independent studying (learning materials are reusable and repeatable) and selfassessment. Students of the covid-19-semester SS2020 rate the course and its assessment in agreement to students who attended the blended learning classes (Figure 3). Although the course could be easily managed from a distance approximately $65 \%$ of the course attended the online sessions time regularly.

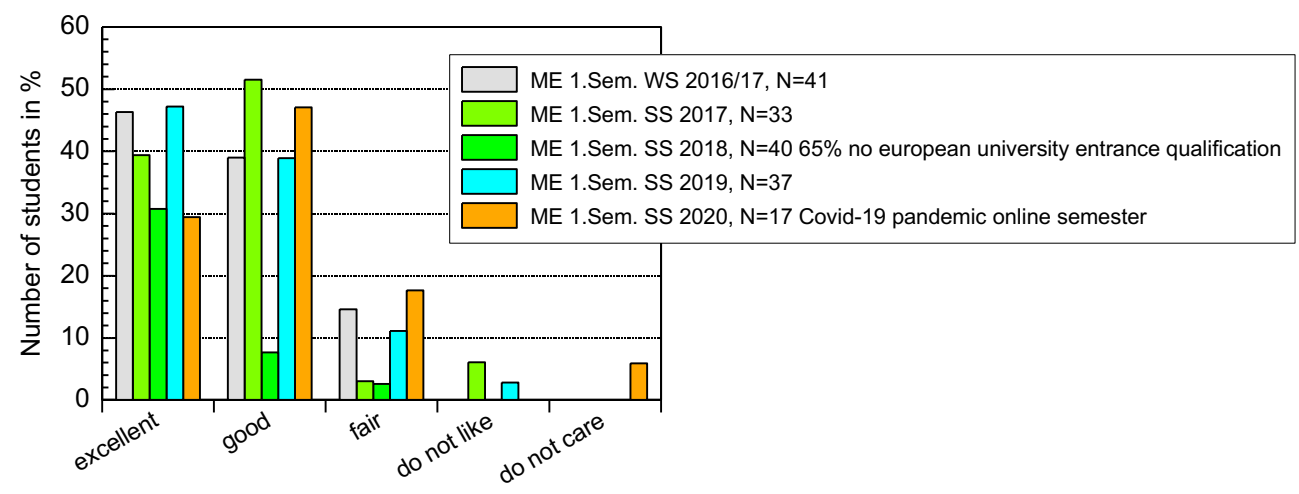

Overall rating of material science course

Figure 3. Evaluation of the material science course with regard to the cumulative assessment SS2016 to SS2020.

Indeed, students with migration background and language problems generally scored lower in tests due to time limits and difficulty in reading and understanding questions without using a dictionary. But, because the different activities offered enough possibilities to pass the class and even score high, they put a lot of effort into their studies - and in SS2020 even scored $\mathrm{A}+$ (Figure 2). In the pandemic online semester of SS2020 the diversity in learning outcome was reduced and homogeneity regarding language background enhanced. It seems that with all students forced to study self-directed with no classroom interaction and forced teaching situations language problems were overcome. Note, students with the same language background formed rather homogeneous study groups with speaking French or Arabic during group work. Usually these language problems are a big obstacle for the homogeneity of a class but did not account for the pandemic covid-19 semester 2020. Generally, students were 
given more responsibility for their learning progress during the semester which was found to encourage critical thinking: CSU (2015), that results in deeper learning outcomes: Simon et al. (2010). The author wants to remind, that all the advantages may be lost when onlinesessions are used for knowledge transfer only. It is highly recommended that online time is used for explanations and small group work in break-out sessions. In these more individual and hence safer environments students are more lively, ask questions and feel addressed in person which is directly related to good leraning outcome. Small groups, individual positive feedback and also phone calls on the well being and study progress seemed to be essential for students to reach the course learning objectives.

It is important to note, that the cumulative micro-grading assessment method (Figure 3) and inverted classroom micro lectures directly connects the course assessments to the course learning objectives without being only a series of separate course assignments: Carberry et al. (2012). Grades are weighed and summed anonymously offering the lecturer to be less biased therefore students grades are more substantial: CSU (2015). Advantageously, the grading offers transparency and does not push student work towards the end but is equally distributed throughout the semester. Despite the discussion on the value of teaching in present (which we fully agree with) here especially students with language difficulties felt reassured of their learning skills in the fully online environment without the pressure of the presence in course, perform orally, understand during class and a single final exam.

\section{Conclusion}

Because the diversity of first year students at applied universities is high such as: different educational backgrounds, languages spoken and various social duties next to studying the (online) course concept is of interest to lecturers in higher education. To reduce diversity in material science for mechanical engineering the former blended learning concept was redirected to a fully online concept in the covid-19 semester of SS2020. Inverted classroom scenarios based on micro lectures and peer-to-peer lecture films, glossary and forum entries, group and single homework and traditional quizzes offer a portfolio of various standards. Cumulatively micro grades sum to a total over the entire semester as an alternative to traditional final-test grading. Knowledge transfer was achieved in self-study periods facilitated by the lecturer. Online-teaching sessions were strictly used for feedback, answering questions, group projects and soving hand-on problems. The learning-outcome was enhanced meeting certain boundary conditions, such as alignment of teaching material, especially lecture films and micro lectures, with the course objective. Without the pressure to understand or perform during present class especially students with language difficulties benefitted from the teaching and assessment method. The possibility to achieve high showing different skills, feedback on the learning progress and a transparent grading system during 
the semester enhanced homogeneity of the class with special respect to language difficulties.

\section{References}

Ashby, M., Shercliff, H., Cebon, D. (2013). Materials Engineering, Science, Processing and Design, 2013: ISBN-13: 978-0080994345, Pub date: Oct 02, 2013 (3 ${ }^{\text {rd }}$ edition).

Berrett, D. (2012) How 'flipping' the classroom can improve the traditional lecture. The Cronicle of Higher Education.

Brame, C.J. (2015). Flipping the Classroom, http://cft.vanderbilt.edu/files/Flipping-theclassroom.pdf, call: 09/2015.

Carberry, A.R., Siniawski, M.T., Dionisio J.D.N. (2012). Standards-based grading: Preliminary studies to quantify changes in affective and cognitive student behaviors. IEEE Frontiers in education conference, Seattle, WA.

Colorado State University (2015). Using Peer Teaching in the Classroom. http://teaching.colostate.edu/tips/tip.cfm?tipid=180.

Guskey, T. R. and Pollio H. R. (2012). Grading Systems - School, Higher Education Students, Grades, Teachers, and Learning. Education Encyclopedia-StateUniversity.

Heywood, J. (2014). The evolution of a criterion referenced system of grading for engineering science coursework, IEEE Frontiers in education conference, Madrid, Spain.

Marbouti, F. (2016). Diefes-Dux H. A., Madhavan K., Models for early prediction of at-risk students in a course using standards-based grading, Computers \& Education, 103, 1-15.

Pfennig, A. (2016). Inverting the Classroom in an Introductory Material Science Course, Procedia - Social and Behavioral Sciences, 228, 32-38.

Pfennig, A. (2018). Improvement of learning outcome in material science through inverted classroom techniques and alternative course assessment. JFLET Journal of Foreign Language Education and Techn., 3/1, 148-162.

Pfennig, A. (2019). "Making it Work" - Practice Examples of Preparation and Embedding Peer-to-Peer Lecture Films in Successful Inverted Classroom Scenarios. PEOPLE: International Journal of Social Sciences, 5/1, 640-655.

Pfennig, A. (2020) Improving learning outcome for GSL (German as a Second Language) students in a blended learning cumulative assessment material science course. Int. Conf. on Education and E-Learning ICEEL 2020, 06-08.Nov., Tsuru, Japan (online).

Sadler D. R. (2005). Interpretations of criteria-based assessment and grading in higher education. Assessment \& Evaluation in Higher Education, 30/2, 175-194, online 2010.

Setren, E., Greenberg, K., Moore, O., Yankovich, (2019). Effects of the Flipped Classroom: Evidence from a Randomized Trial, SEII Discussion Paper \#2019.07, MIT Department of Economics, National Bureau of Economic Research.

Simon, B., Kohanfars, M., Lee, J., Tamayo, K, \& Cutts, Q. (2010). Experience report: peer instruction in introductory computing. Proceedings of the 41st ACM Technical Symposium on Computer Science Education, 341-345. 